East African Medical Journal Vol. 77 No. 12 December 2000

NEURO-VASCULAR INJURIES ASSOCIATED WITH LIMB FRACTURES

T. M. Mirdad, MD, FRCSC, College of Medicine and Medical Sciences and Assir Central Hospital, King Khalid University, P.O. Box 641 Abha, Saudi Arabia

\title{
NEURO-VASCULAR INJURIES ASSOCIATED WITH LIMB FRACTURES
}

\author{
T. M. MIRDAD
}

\begin{abstract}
Objective: To study the pattern of trauma cases of the extremities associated with neurovascular injury seen at Assir Central Hospital and to evaluate the results and complications in relationship to the modality of treatment.

Design: A retrospective study.

Settings: Department of Orthopaedics and Traumatology, Assir Central Hospital, Abha, Saudi Arabia.

Subjects: Forty three patients with bone fractures associated with vascular and peripheral nerve injury seen at the Emergency Room of Assir Central Hospital from 1990 to 1999. There were 39 males and four females. Thirty five of these patients $(\mathbf{8 1 . 4 \%})$ were Saudi nationals and the rest were non-Saudi. The age range was between 7.5 and 65 years (average 29.6 years).

Interventions: All the patients were operated on, and the procedure performed depended on the nature of the injury sustained.

Results: Road traffic accidents were the main cause of fractures associated with neurovascular injury. The most commonly fractured bone was humerus $(17.1 \%)$ and the most commonly injured vessel was brachial artery $(32.4 \%)$. The most commonly injured nerve was radial nerve $(50 \%)$. There was one mortality, two cases each of below knee amputation, Volkmann's ischaemic contracture of the forearm and above elbow amputation.

Conclusion: Road traffic accidents were a major cause of traumatic morbidity and mortality in Saudi Arabia.
\end{abstract}

\section{INTRODUCTION}

Trauma frequently involves the bones of the extremities. This can also involve the vessels and the nerves of the extremities either directly from the initial injury or secondarily from the fragments of the fractured bone. It was therefore decided to study the pattern of trauma cases of the extremities associated with neurovascular injury seen at Assir Central Hospital, and to evaluate the results and complications of our modality of treatment.

\section{MATERIALS AND METHODS}

In a ten year period, from 1990 to 1999 , forty three patients with bone fractures in association with vascular and peripheral nerve injuries were retrospectively studied. The case notes of all the patients with vascular or nerve injury associated with fractures and trauma were studied. The nature of the trauma, the vessels and nerves involved and associated fractures were recorded. Attempt was made to determine whether the fracture caused the neuro-vascular injury or whether the trauma caused both together at the same time, at the time of injury. The methods of treatment given were also recorded and correlated with the results.
Findings: Forty three cases of trauma to both lower and upper extremities were found to be associated with either vascular or nerve injuries. Five of these cases with neurovascular injuries had no associated fractures. There was one case of elbow dislocation following a fall from height, one crush injury of the forearm without fracture, and three cases of gunshot wound of the thigh. There was evidence to conclude that the majority of the vascular and nerve damage might have occurred at the time of injury and not necessarily secondary to trauma by fractured bony fragments although this could also occur. However, there was no strong evidence to confirm this, apart from the five cases (11.6\%) that had neuro-vascular injuries not associated with fractures.

The age range of the patients was between 7.5 years and 65 years (average 29.6 years). The male to female ratio was 9.8 to 1.0. There were 39 males and four females. Thirty five patients $(81.4 \%)$ were Saudi nationals and the rest were non-Saudi nationals. There were three Indians, two Egyptians, one Pakistani and one Bangladeshi.

Road traffic accident was primarily responsible for this type of injury, 29 cases (67.4\%) followed by crush injury, seven cases $(16.3 \%)$ and gunshot injury, seven cases (16.3\%).

Since most of these patients sustained multiple fractures, 43 patients sustained a total of 82 fractures. The most common fracture sustained was humeral fracture, 14 cases $(17.1 \%)$ followed by tibial fracture, 12 cases (14.6\%) (Table 1). For an unexplained reason most of the fractures $(58.5 \%)$ occurred on 
the left side of the body and the rest $(41.5 \%)$ occurred on the right side.

Brachial artery was the most commonly injured artery, 11 cases $(32.4 \%)$ followed by the radial artery, five cases $(14.75 \%)$ as shown in (Table 2). There was one case of traumatic dissecting abdominal aortic aneurysm. Radial nerve was the most commonly injured nerve, six cases $(50 \%)$ followed by ulnar nerve, three cases $(25 \%)$ (Table 3 ).

Table 1

Neuro-vascular injuries associated with limb fractures

\begin{tabular}{lccr}
\hline Type of fracture & Left & Right & Total \\
\hline Humerus & 11 & 3 & $14(17.1 \%)$ \\
Elbow (Olecranon, lateral & & & \\
condyle) & 7 & 2 & $9(11.0 \%)$ \\
Radius & 5 & 4 & $9(11.0 \%)$ \\
Ulna & 2 & 4 & $6(7.3 \%)$ \\
Neck of femur & - & 2 & $2(2.4 \%)$ \\
Femoral shaft & 4 & - & $4(4.8 \%)$ \\
Knee (patella) & 2 & 1 & $3(3.7 \%)$ \\
Tibia & 6 & 6 & $12(14.6 \%)$ \\
Fibula & 3 & 5 & $8(9.8 \%)$ \\
Clavicle & 2 & 1 & $3(3.7 \%)$ \\
Scapula & 1 & - & $1(1.25 \%)$ \\
Pelvic & - & 3 & $3(37 \%)$ \\
Metacarpals & 4 & 3 & $7(8.5 \%)$ \\
Talus & 1 & - & $1(1.25 \%)$ \\
\hline Total & $48(58.5 \%)$ & $34(41.5 \%)$ & $82(100 \%)$ \\
\hline
\end{tabular}

Table 2

Neuro-vascular injuries associated with limb fractures

\begin{tabular}{lr}
\hline Vessel injured & No $(\%)$ \\
\hline Brachial artery & $11(32.4)$ \\
Radial artery & $5(14.7)$ \\
Ulnar artery & $4(11.8)$ \\
Femoral artery & $4(11.8)$ \\
Popliteal artery & $4(11.8)$ \\
Axillary artery & $2(5.9)$ \\
Tibial artery & $1(2.9)$ \\
Posterior tibial artery & $1(2.9)$ \\
Digital vessels & $1(2.9)$ \\
Traumatic dissecting aortic aneurysm & $1(2.9)$ \\
\hline Total & $34(100)$ \\
\hline
\end{tabular}

Table 3

Neuro-vascular injuries associated with fractures

\begin{tabular}{lc}
\hline Nerve injured & No $(\%)$ \\
\hline Radial nerve & $6(50)$ \\
Ulnar nerve & $3(25)$ \\
Median nerve & $1(8.3)$ \\
Posterior interosseous nerve & $1(8.3)$ \\
Common peroneal nerve & $1(8.3)$ \\
\hline Total & $12(100)$ \\
\hline
\end{tabular}

\section{Table 4}

Neuro-vascular injuries associated with limb fractures

\begin{tabular}{lr}
\hline Modality of arterial repair & No. $(\%)$ \\
\hline Arterial reconstruction using venous patch or & \\
venous graft & $15(44.1)$ \\
Arterial end-to-end anastomosis & $6(17.6)$ \\
Embolectomy and vascular repair & $4(11.8)$ \\
Embolectomy alone & $4(11.8)$ \\
Embolectomy and a by-pass graft & $1(2.9)$ \\
Only exploration of vessel & $4(11.8)$ \\
\hline Total & $34(100)$
\end{tabular}

Management: Most of the fractures were treated by open reduction and internal fixation, and the rest by the use of external fixators. Most of the injured nerves were found contused but not transected. The transected ones were primarily repaired but those that were contused, stretched or compressed were treated by a wait-and-see approach for a re-assessment after a period of about three months.

The injured arteries were primarily treated by arterial reconstruction using venous patch or vein graft from long saphenous and cephalic veins. These were done in 15 cases $(44.1 \%)$ (Table 4$)$. One case of transected popliteal vein in association with injured popliteal artery also had an end-to-end anastomosis of the vein.

Because of anticipation of development of compartment syndrome, fasciotomy was performed in fifteen cases $(44.1 \%)$ of all explored for vascular injuries.

\section{RESULTS}

There was one death in this series of 43 patients. This was a seventeen-year old patient who had fractured femur and lacerations of femoral artery and vein. He developed crush syndrome, renal shut down, gangrene of the leg, disseminated intravascular coagulation (DIC) and acute respiratory distress syndrome (ARDS). Two patients (4.7\%), had below knee amputation. One was a case of infected end-to-end anastomosis of popliteal artery injury. The other was a case of dissecting abdominal aortic aneurysm that was successfully repaired, but four weeks later had to have amputation of the right leg because of gangrene. Two patients (4.7\%) also had Volkmann's ischaemic contracture of the arm, and two other patients (4.7\%) needed above elbow amputation for gangrene, but discharged themselves. The remaining 36 patients $(83.7 \%)$ had a satisfactory outcome.

The nerves that did not make full recovery after treatment were mainly peroneal, median, musculocutaneous, sciatic and ulnar nerves.

\section{DISCUSSION}

When nerve and vascular injuries are associated with a traumatic fractured limb, the tendency is to attribute the nerve and vascular injuries to the fractured bone fragments. Yet, it would seem as if the initial trauma causing the fracture may, in some cases, be responsible for the nerve 
and vascular injuries. In this series there are three cases of gunshot wounds of the thigh, one case of crush injury of the forearm and one case of elbow dislocation without any fracture of bones but with vascular and nerve injuries.

The average age in this series is 29.6 years, and male to female ratio of 9.8 to 1.0 tends to suggest that these serious injuries tend to occur in people engaged in active and probably dangerous activities in the most productive stage of their lives. Like all previous reports on injuries in this environment(1-3), road traffic accidents were primarily responsible for this type of injury (67.4\%). This is a testimony to the fact that something needs to be done urgently, concerning the driving of vehicles in this country. The most commonly injured areas, humerus and elbow $(29.1 \%)$ (Table 1 ) correlate well with the most commonly injured vessel, brachial artery (32.4\%) (Table 2).

Arterial injury associated with hip fracture is uncommon, however, a case of pseudo-aneurysm of the profunda femoris artery that presented four weeks after correction of an intertrochanteric hip fracture with a dynamic hip screw has been reported(4). Pseudo-aneurysm of the superficial femoral artery following trauma has also been reported(5). A case of deep venous thrombosis caused by a popliteal false aneurysm from an avulsion fracture of the femur has also been reported(6). Usually arterial damage following blunt trauma is uncommon and is usually the result of high-energy injury. However, a case of posterior tibial artery rupture after a closed distal tibial fracture sustained during a low-energy soccer tackle has been reported(7) and cases of axillary artery injury after proximal humerus fracture have also been reported $(8,9)$. Association of vascular injuries with pelvic fractures is not uncommon. The injured vessels may be a torn internal pudendal artery(11) or bleeding from small arterial branches of the internal iliac artery(12). However, blunt trauma associated with superior gluteal artery rupture without pelvic fracture causing profound hypotension has been reported(13). Vessels of the forearm are also commonly injured in trauma to the upper limbs. Checroun et al(14), reported three cases of radial artery injury in association with fractures of the trapezium.

One patient in this series had a traumatic dissecting abdominal aortic aneurysm. This case is similar to the case of traumatic aorto-iliac dissection injury in a child with pelvic fracture(15) previously described.

The modality of treatment of injured nerves adopted in this series was the method recommended by many authors((16-18). Primary repair of cleanly divided nerve is advocated and non-operative treatment of nerve injuries associated with closed fractures is advocated unless there are no signs of nerve regeneration in two to three months. This series also agrees with the observations of some authors that in civilian traumatic injury, nerve injury is more common with the trauma of the arm than in the $\operatorname{leg}(19,20)$.

The cases needing amputation in this series from neuro-vascular injuries are comparable to the series of others, previously reported $(21,22)$. There are certain factors believed to increase the rate of amputation in patients with blunt injuries to the lower limb associated with arterial injury. Faris et al(23) believed that the major factor determining outcome was the severity of the soft-tissue injury. Progressive necrosis and infection were major causes of late amputation. Also, the outcomes of tibial fractures with an associated vascular injury are poorest in older patients who are at risk of amputation, and in those with an injury to the posterior tibial artery who are at increased risk of delayed union and non-union(24).

Some of the fractures in this series were treated by external fixators. The use of external fixation has been shown in complicated fractures to allow associated injuries to the nerves, arteries and soft tissues to be treated adequately while maintaining skeletal stability(25).

\section{CONCLUSION}

Road traffic accidents were the most common cause of neurovascular injury in this environment. The most commonly fractured bone was humerus and the most commonly injured artery was brachial artery. The most commonly injured nerve was the radial nerve.

\section{REFERENCES}

1. Batouk A.N., Abu-Eisheh, N., Abu-Eshy S., Al-Shehri M., AlNaami M. and Jastaniah S. Analysis of 303 road traffic accident victims seen dead on arrival at Emergency Room - Assir Central Hospital. J. Famil. Comm. Med. 1997; 3:29-34.

2. Khan M.R.H. and Mirdad T.M. Musculoskeletal injuries in a major road traffic accident. Ann. Saudi Med. 1997; 17:444-6.

3. Mirdad T. The pattern of pelvic fractures in Assir region of Saudi Arabia. Bahrain Med. Bull. 1998; 20:41-3.

4. Murphy P.G., Geoghegan J.G., Austin O., More O'Ferrall R., Quinlan W.R. and Keaveny T.V. Pseudoaneurysm of the profunda fermoris artery due to intertrochanteric fracture of the hip. Arch. Orthop. Trauma Surg. 1999; 119: 117-8.

5. Sharma S., Bhargava B., Mahapatra M. and Malhotra R. Pseudoaneurysm of the superficial femoral artery following accidental trauma: result of treatment by percutaneous stent-graft placement. Eur. Radiol. 1999; 9: 422-4.

6. Dresner S.M., Banerjee B., Owen R. and Lees T.A. A popliteal false aneurysm caused by an avulsion fracture of the femur: a case presenting with deep venous thrombosis. Eur. J. Vasc. Endovasc. Surg. 1999; 17: 180-2.

7. Tytherleigh M.G., Charnley G.J. and Wilkins D.C. Closed rupture of the posterior tibial artery secondary to a soccer injury. Ann. roy. Coll. Surg. Engl. 1998; 80: 266-8.

8. McLaughlin J.A., Light R. and Lustrin I. Axillary artery injury as a complication of proximal humerus fractures. J. Shoulder Elbow Surg. 1998; 7: 292-4.

9. Van-Arkel E.R., Tordoir J.H. and Arens H.J. A proximal humeral fracture, complicated by a pseudoaneurysm - a case report. Acta Orthop. Scand. 1998; 69:194-5.

10. Byrd R.G., Byrd R.P. Jr and Roy T.M. Axillary artery injuries after proximal fracture of the humerus. Amer. J. Emerg. Med. 1998;16: 154-6.

11. Wholey M., Peterson S. and Silvestri B. Pelvic fracture with tear of the left internal pudendal artery. Amer. J. Roentgenol. 1998; 171: 844-848.

12. Perez J.V., Hughes T.M. and Bowers K. Angiographic embolisation in pelvic fracture. Injury 1998; 29: 187-91. 
13. Belley G., Gallix B.P., Derossis A.M., Mulder D.S. and Brown R.A. Profound hypotension in blunt trauma associated with superior gluteal artery rupture without pelvic fracture. J. Trauma 1997; 43: 703-5.

14. Checroun A.J., Mekhail A.O. and Ebraheim N.A. Radial artery injury in association with fractures of the trapezium. J. Hand. Surg. Br 1997; 22: 419-22.

15. Namasivayam S., Sathyanathan J. and Saker N. Rare traumatic aorto-iliac dissection injury in a child with pelvic fracture and urethral rupture: a case report. J. Paediat. Surg. 1997; 32: 638-40.

16. Frykman G.K. Peripheral nerve injuries in children. Orthop. Clin. North Amer. 1976; 7:701-16.

17. Panitz K., Neundorfer B. and Piotrowski W. Prognosis of nerve injuries in humeral fractures. Chirurg. 1975; 46: 392-4

18. Ehni B.L. Treatment of traumatic peripheral nerve injury. Amer. Family Phys. 1991; 43: 897-905.
19. Visser P.A., Hermreck A.S., Pierce G.E., Thomas J.H. and Hardin C.A. Prognosis of nerve injuries incurred during acute trauma to peripheral arteries. Amer. J. Surg. 1980; 140: 596-9.

20. Nichols J.S. and Lillehei K.O. Nerve injury associated with acute vascular trauma. Surg. Clin. N. Amer. 1988; 68: 837-52.

21. Roberts C., Ruktanonchai D., King D. and Seligson D. Vascular compromise and amputation after intramedullary nailing of a tibia fracture. J. Orthop. Trauma 1998; 12:136-8.

22. Sriussadaporn S. Arterial injuries of the lower extremity from blunt trauma. J. Med. Ass. Thai 1997; 80:121-9.

23. Faris I.B., Raptis S. and Fitridge R. Arterial injury in the lower limb from blunt trauma. Aust. N. Z. J. Surg. 1997; 67: 25-30.

24. Brinker M.R. and Bailey D.E. Jr. Fracture healing in tibia fractures with an associated vascular injury. J. Trauma. 1997; 42:11-9.

25. Mostafavi H.R. and Tornetta P. 3rd. Open fractures of the humerus treated with external fixation. Clin. Orthop. 1997; 337: 187-97.

\title{
KENYA OBSTETRICAL AND GYNAECOLOGICAL SOCIETY
}

\author{
announces
}

\section{6th Annual Scientific Conference}

21st to 23rd February 2001

Venue: Holiday Inn (Mayfair Court Hotel), Nairobi

Theme: SAFE MOTHERHOOD AND ITS CHALLENGES

"Imagine a World where motherhood is safe for all women.

You can help make it happen"

Mahmoud Fathala FIGO 2000

Call for papers, to be submitted by 15 th December 2000

For more information contact:

Conference Secretariat,

Kenya Obstetrical and Gynaecological Society,

P.O. Box 19459, Nairobi, Kenya, e-mail: kogs@ healthnet.or.ke 